\title{
IDENTIFIKASI KELAYAKAN OBYEK WISATA ALAM DENGAN PENDEKATAN 4A (ATTRACTION, AMENITY, ACCESIBILITY, DAN ANCILLIARY)
}

\author{
Ibnu Setyo Yuliardi ${ }^{1}$, Anityas Dian Susanti ${ }^{2}$, Ratri Septana Saraswati ${ }^{3}$ \\ Program Studi Arsitektur, Fakultas Teknik, Universitas Pandanaran Semarang ${ }^{12}$ \\ Program Studi Arsitektur, Fakultas Teknik, Universitas PGRI Semarang ${ }^{3}$ \\ ibnusyardi@gmail.com ${ }^{1}$ \\ tyas@unpand.ac.id² \\ ratriseptiana@upgris.ac.id ${ }^{3}$
}

\begin{abstract}
One of the crucial sectors in order to encourage the national economy is tourism. So for that the Indonesian government is currently serious about dealing with the problem of tourism potential in this country. Indonesia has the potential for tourism objects that are so large because Indonesia is a maritime country and an archipelagic country. Kabupaten Semarang saves a lot of tourist charms including natural charms that are still natural and also amazing, and there are still many people or tourists and tourism investors who do not know about the potential of tourism objects in Semarang Regency, one of which is natural tourism. The development of the tourism industry in Kabupaten Semarang has a great impact on regional development in the tourism object area, so that it can be said to be a "Superior Industry" that can improve the regional economy. Because there is quite a lot of tourism potential in Semarang Regency, a study was conducted to identify the feasibility of existing tourism potential in Semarang Regency with the 4A approach method, namely Attraction, Amenity, Accessibility, and Ancilliary. Although the development of tourism in Semarang Regency has not developed optimally, there are tourist destinations that are very popular with tourists to visit such as Lawe \& Benowo Waterfalls Ungaran, Semirang Ungaran Waterfall, and Ngipik Pass Ungaran.
\end{abstract}

Keywords: Tourism, Kabupaten Semarang, Waterfall, 4A, Curug Lawe \& Benowo, Curug Semirang, Ngipik Pass

Abstrak

Salah satu sektor krusial dalam rangka mendorong perekonomian nasional yaitu Pariwisata. Maka untuk itu pemerintah Indonesia saat ini serius menangani masalah potensi pariwisata yang ada di negara ini. Indonesia mempunyai potensi obyek pariwisata yang begitu besar karena indonesia merupakan sebuah negara maritim dan negara kepulauan. Kabupaten semarang menyimpan banyak pesona wisata meliputi pesona alam yang masih alami dan juga menakjubkan, dan masih banyak masyarakat atau wisatawan dan investor pariwisata yang belum tahu akan potensi obyek wisata yang ada di Kabupaten Semarang salah satunya yaitu wisata alam. Pengembangan industri pariwisata di Kabupaten Semarang mempunyai dampak yang besar bagi perkembangan wilayah di area obyek wisata tersebut, sehingga dapat dikatakan sebagai "Industry Unggulan" yang bisa meningkatkan ekonomi daerah. Karena potensi wisata di Kabupaten Semarang cukup banyak, maka diadakan penelitian untuk mengidentifikasi kelayakan potensi wisata yang ada di Kabupaten semarang dengan metode pendekatan 4A yaitu Attraction (Daya tarik), Amenity (Fasilitas), Accessibility (Aksesibilitas), dan Ancilliary (Lembaga pelayanan). Walaupun perkembangan pariwisata yang ada di Kabupaten Semarang belum berkembang dengan optimal, namun ada tujuan wisata yang sangat digemari wisatawan untuk berkunjung seperti Curug Lawe \& Benowo Ungaran, Curug Semirang Ungaran, dan Ngipik Pass Ungaran

Kata kunci: Pariwisata, Kabupaten Semarang, Curug, 4A , Curug Lawe \& Benowo, Curug Semirang, Ngipik Pass 


\section{PENDAHULUAN}

Salah satu sektor krusial dalam rangka mendorong perekonomian nasional yaitu Pariwisata. Maka untuk itu pemerintah Indonesia saat ini serius menangani masalah potensi pariwisata yang ada di negara ini. Indonesia mempunyai potensi obyek pariwisata yang begitu besar karena indonesia merupakan sebuah negara maritim dan negara kepulauan. Berbicara tentang pengembangan kegiatan pariwisata yang ada di Indonesia sangatlah luas dan juga kompleks. Industri pariwisata memiliki koneksivitas antara sektor lain seperti sector jasa, perdagangan, pertanian, budaya, dan juga sector transportasi. sector jasa, perdagangan, pertanian, budaya, dan juga sector transportasi. Pengembangan dan dayaguna pariwisata secara maksimal akan mampu mendorong meningkatnya pertumbuhan ekonomi yang baik, diantaranya adalah membuka lapangan pekerjaan, meningkatkan ekonomi masyarakat dan meningkatkan ekonomi daerah. Di wilayah kabupaten semarang sendiri potensi pariwisata cukup besar dan harus dimanfaatkan dan dikelola dengan baik. Melihat hal itulah, perkembangan industri wisata di Kabupaten Semarang masih kurang berkembang seperti di kabupaten yang lain seperti kabupaten gunung kidul yang sudah sangat berkembang. Kabupaten Semarang ialah sebuah kabupaten yang ibu kotanya adalah Ungaran terletak di Provinsi Jawa Tengah. Batas kabupatennya yaitu Kota Semarang di sebelah utara, Kabupaten Grobogan dan juga Kabupaten Demak berada di sisi timur, Kota Salatiga di Tengah kabupaten Semarang dan juga Kabupaten Magelang, kabupaten Boyolali di Selatan dan Timur , Kabupaten Temanggung \& Kabupaten Kendal di sebelah Barat. Kabupaten semarang menyimpan banyak pesona wisata meliputi pesona alam yang masih alami dan juga menakjubkan, dan masih banyak masyarakat atau wisatawan dan investor pariwisata yang belum tahu akan potensi obyek wisata yang ada di Kabupaten Semarang salah satunya yaitu wisata alam. Banyak manfaat yang di akibatkan karena berkembangnya pariwisata di suatu daerah, yakni secara manfaat ekonomi, manfaat sosial dan manfaat budaya. Namun permasalahannya Ketika pariwaisata itu tidak dikelola dengan baik, maka malah akan menimbulkan kerugian bagi masyarakat maupun pengelola. Pengembangan industri pariwisata di daerahdaerah mempunyai dampak yang besar bagi perkembangan wilayah di area obyek wisata tersebut, sehingga dapat dikatakan sebagai "Industry Unggulan" yang bisa meningkatkan ekonomi daerah. Karena potensi wisata di Kabupaten Semarang cukup banyak, maka diadakan penelitian untuk mengidentifikasi kelayakan potensi wisata yang ada di Kabupaten semarang dengan metode pendekatan 4A yaitu Attraction (Daya tarik), Amenity (Fasilitas), Accessibility (Aksesibilitas), dan Ancilliary (Lembaga pelayanan). Walaupun perkembangan pariwisata yang ada di Kabupaten Semarang belum berkembang dengan optimal, namun ada tujuan wisata yang sangat digemari wisatawan untuk berkunjung seperti Curug Lawe \& Benowo Ungaran, Curug Semirang Ungaran, dan Ngipik Pass Ungaran

\section{TINJAUAN TEORI Pariwisata}

Secara bahasa, pariwisata berasal dari Bahasa Sansekerta, yang berarti pari yaitu "banyak" atau "berkeliling" dan wisata berarti "pergi" atau "bepergian". Menurut

Program Studi Arsitektur Universitas Pandanaran | kolaborasi_jurnal@unpand.ac.id | 37 
Wahid (2015), pariwisata adalah perjalanan sementara dari satu tempat ke tempat lain yang dilakukan secara individu atau kelompok dan memiliki tujuan untuk menemukan kebahagiaan dan keseimbangan dengan lingkungan dalam bidang sosial, budaya, ilmu pengetahuan dan alam. b) Menurut Muljadi (2009), pariwisata adalah rangkaian kegiatan bersifat sementara berupa perjalanan yang dilakukan oleh perorangan atau kelompok dari tempat tinggalnya ke tempat lain dalam rangka melakukan kunjungan wisata dan bukan untuk bekerja.

\section{Identifikasi}

Identifikasi diambil dari kosakata bahasa Inggris yaitu Identify yang artinya adalah meneliti/ menelaah. Identifikasi ialah kegiatan untuk menyelidiki, mencatat, menemukan, mengumpulkan, meneliti, mendata dan menginformasikan tentang "kebutuhan" lapangan. Menurut Yusuef (2014) Identifikasi ialah suatu kegiatan yang tujuannya adalah untuk menganalisis dan mengkaji suatu hal atau objek secara lebih rinci. Arti secara umum adalah suatu tindakan atau proses untuk meneliti, mencari, menemukan, mencatat informasi dan data tentang suatu fakta, suatu tempat atau seseorang.

\section{Obyek Wisata}

Obyek wisata adalah suatu tempat yang mempunyai daya tarik agar masyarakat ingin datang untuk berkunjung ke tempat itu. Obyek wisata dapat berupa wisata alam seperti air terjun, perbukitan, pegunungan, sungai, danau, laut, pantai atau berupa obyek wisata buatan seperti kolam renang, arena bermain, bangunan museum, bangunan benteng, situs-situ peninggalan sejarah, dan lainnya.

\section{Konsep 4A}

Menurut Cooper (2010), mengatakan untuk memenuhi segala asas kebutuhan dan juga pelayanan pariwisata suatu obyek wisata haruslah didukung oleh 4 (empat) elemen utama dalam pariwisata yaitu: Attraction (Daya tarik), Amenity (Fasilitas), Accessibility (Aksesibilitas), dan Ancilliary (Lembaga pelayanan) atau biasa dikenal dengan istilah " $4 \mathrm{~A}$ ".

1. Attraction ( Daya Tarik)

Attraction atau atraksi atau daya Tarik merupakan andalan sebuah Obyek wisata dan saling terkait dengan apa yang bisa dilihat dan dilakukan oleh wisatawan pada suatu obyek wisata. Menurut Suwena (2010) atraksi wisata merupakan elemen yang sangat penting yang dapat menarik kedatangan pelaku wisata.

\section{Accessibility (Aksesibilitas)}

Agar memudahkan para wisatawan mengunjungi ke berbagai object wisata, maka harus dibarengi oleh akomodasi yang memadai diantaranya adalah sarana transportasi. Faktor terkait aksesibilitas seperti tanda petunjuk arah, lokasi bandara, lokasi terminal, berapa waktu yang ditempuh, berapa biaya berwisata, dan tentang transportasi menuju lokasi wisata juga tidak kalah penting (Sunaryo, 2013).

\section{Amenity (Fasilitas)}

Sugiama (2011) menjabarkan bahwa fasilitas adalah segala macam sarana dan prasarana pendukung selama pelaku wisata berada di suatu object wisata. Sarana dan prasarana tersebut meliputi penyediaan akomodasi, kebutuhan makan dan minum, memiliki area untuk mengadakan pertunjukan, memiliki tempat hiburan dan juga tempat belanja. Adapun prasarananya adalah seperti persediaan air bersih, adanya listrik, tempat sampah, halte, stasiun kereta, bandara, pelabuhan, teknologi komunikasi dan lainnya. 
4. Ancillary (Lembaga Pelayanan)

Menurt Sugiama (2011) ancillary atau pelayanan tambahan adalah adanya lembaga kepariwisataan yang resmi yang mengaturnya dan juga yang dapat memberikan dampak wisatawan merasa aman dan terlindungi. Lembaga tersebut memudahkan pelaku wisata dengan berbagai layanan seperti informasi, keamanan dan lainnya.

\section{Potensi Wisata}

aMenurut Sukardi (1998) potensi wisata ialah segala hal yang dimiliki oleh suatu tempat sebagai daya tarik yang berguna untuk dikembangkan menjadi object wisata.

Menurut Mariotti tahun 1996 segala sesuatu yang merupakan daya tarik agar masyarakat mau berkunjung ke tempat wisata tersebut dan dimiliki oleh tempat wisata tersebut.

\section{Wisata Curug}

Curug berasal dari Bahasa sunda yang mempunyai arti Air terjun. Curug adalah sebuah keindahan alam dengan bentukan geologi yang berasal dari mata air yang mengalir dari tempat tinggi ke tempat rendah yang melewati bebatuan yang mengalami berbagai macam jalur-jalur erosi. Curug atau air terjun biasanya terbentuk di lingkungan dimana erosi sering terjadi yaitu pegunungan.

\section{Wisata Pass}

Wisata Pass atau wisata puncak adalah berupa wisata alam yang lokasinya berada di puncak bukit dengan maksud menikmati keindahan alam yang terlihat dari atas. Yang menjadi potensi dari wisata pass adalah pemandangan alamnya yang cantik. Pemandangan yang ditawarkan bisa berupa pepohonan, persawahan, sungai , perkotaan, maupun hanya ingin menikmati suasana kemunculan matahari pagi.

\section{METODOLOGI PENELITIAN}

Pendekatan yang di gunakan penelitian ini adalah pendekatan kualitatif. Karena Permasalah penelitian ini lebih banyak berhubungan dengan manusia dan bergantung pada pengamatan. Ristekdikti menjabarkan bahwa prosedur yang disarankan dalam penelitian adalah penelitian kualitatif yang memanfaatkan data deskriptif, yaitu data berupa kalimat tertulis atau ucapan dari masyarakat dan obyek yang dapat diamati. Penelitian kualitatif dipilih karena bisa menjelaskan dan menganalisa peristiwa, dinamika social, fenomena, sikap, kepercayaan, dan persepsi masyarakat terhadap sesuatu. Proses penelitian tersebut diawali dengan menyusun data-data dari hipotesis atau dugaan dasar yang akan digunakan dalam penelitian. Data yang telah dikumpulkan tersebut kemudian ditafsirkan. Menurut Nasution (2003) menerangkan bahwa penelitian kualitatif adalah mengamati seseorang atau kelompok masyarakat dalam lingkup penelitian, berinteraksi dengan mereka dengan berusaha memahami apa yang dibicarakan tentang dunia sekelilingnya".

\section{HASIL PEMBAHASAN}

Identifikasi potensi wisata dengan metode pendekatan 4A (attraction, accesibility, amenity dan ancilliary) - merupakan suatu kegiatan analisis terhadap suatu obyek wisata alam dengan membandingkan kriteria 4A antara wisata alam satu dengan yang lainnya menggunakan tabel kriteria penilaian sehingga diharapkan mendapatkan penilaian kelayakan suatu obyek wisata. Dari hasil tersebut kemudian dikelompokan dengan tabel rekapitulasi sehinggga dapat terlihat wisata mana yang mendapat nilai maksimal dan minimal dan elemen apa saja yang perlu

Program Studi Arsitektur Universitas Pandanaran | kolaborasi jurnal@unpand.ac.id | 39 
pembenahan dengan maksud agar pengelola melakukan upaya apa yang harus dilakukan dalam pengelolaan obyek wisata selanjutnya. Berikut ini analisis pendekatan 4A dari objek wisata Curug Lawe \& benowo, Curug Semirang dan Ngipik Pass.

\section{Curug Lawe \& Benowo}

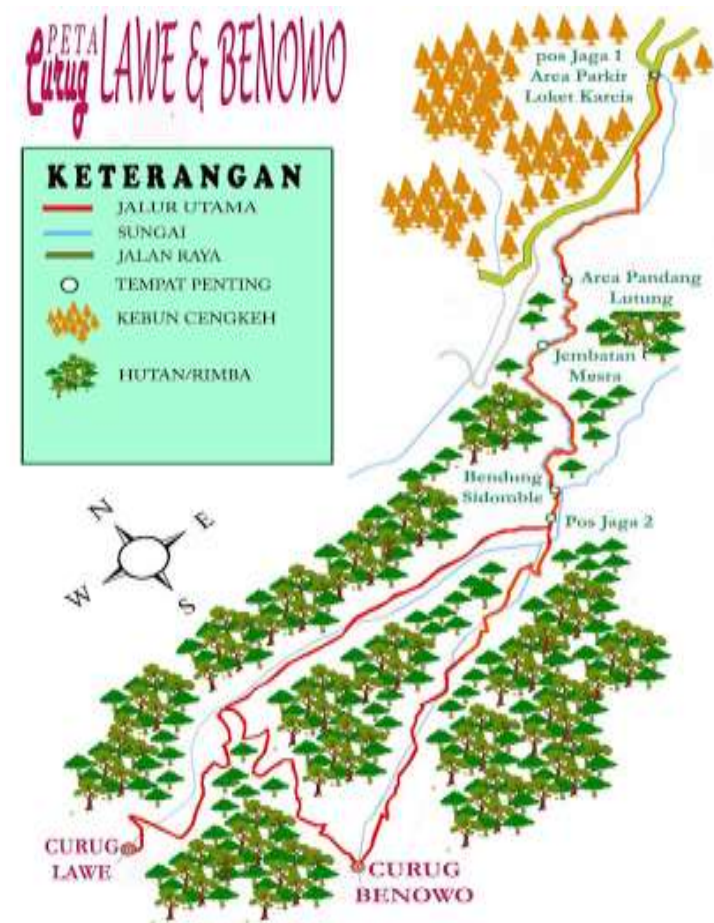

Gambar 1. Peta dari parkiran ke Curug Lawe \& Benowo

A. Attraction ( Daya Tarik) Curug Lawe \& Benowo

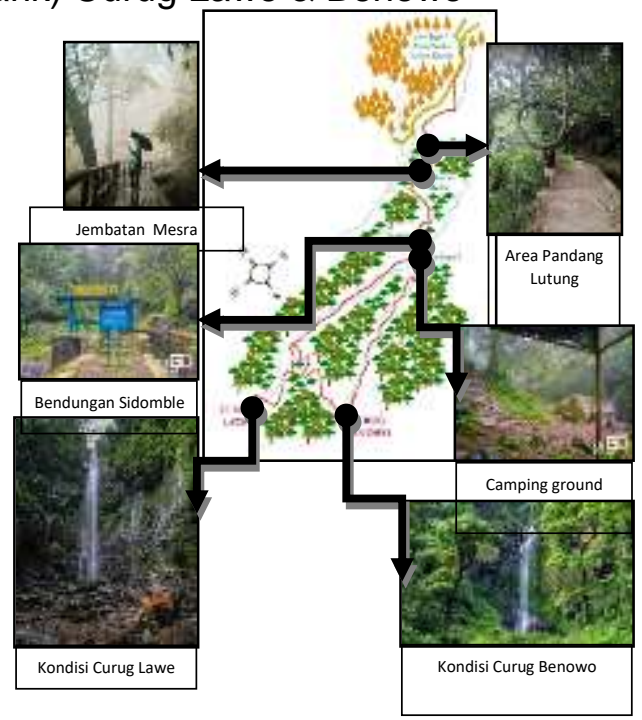

Gambar 2. Kondisi daya tarik Curug Lawe \& Benowo

Daya tarik utama object wisata ini adalah terdapat dua air terjun sekaligus, yaitu Curug Lawe \& Curug Benowo.

40 | Program Studi Arsitektur Universitas Pandanaran | kolaborasi jurnal@unpand.ac.id 
B. Accessibility (Aksesbilitas) Curug Lawe \& Benowo

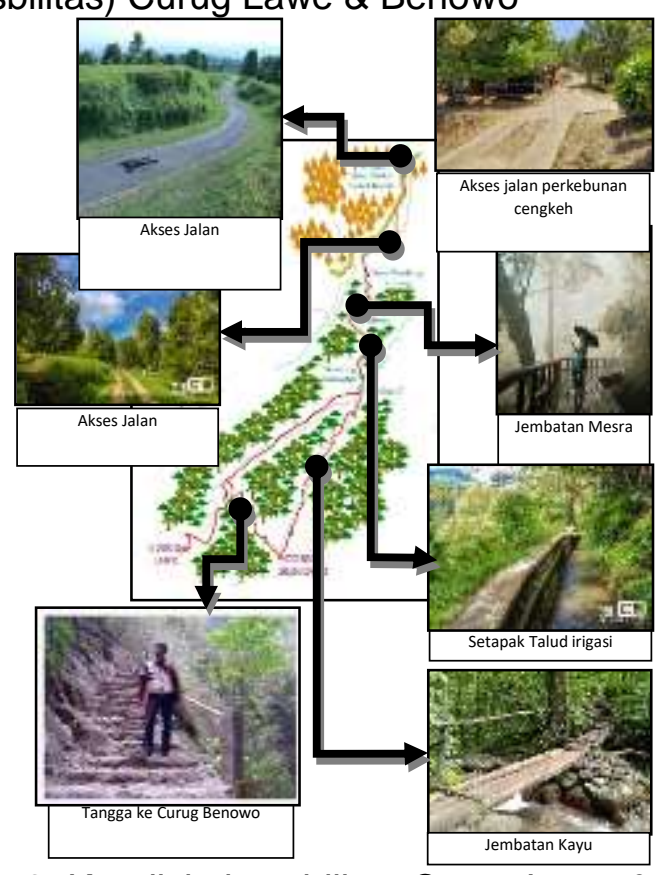

Gambar 3. Kondisi aksesbilitas Curug Lawe \& Benowo

Aksesibilitas wisata Curug Lawe \& Benowo ini melewati kawasan perkebunan cengkih PT Cengkih Zanzibar yang memiliki view pemandangan pegunungan yang sangat indah. Jalan berupa aspal dengan lebar kurang lebih 3 meter dan bisa dilewati kendaraan roda 4 maupun roda 2.

C. Amenity ( Fasilitas) Curug Lawe \& Benowo

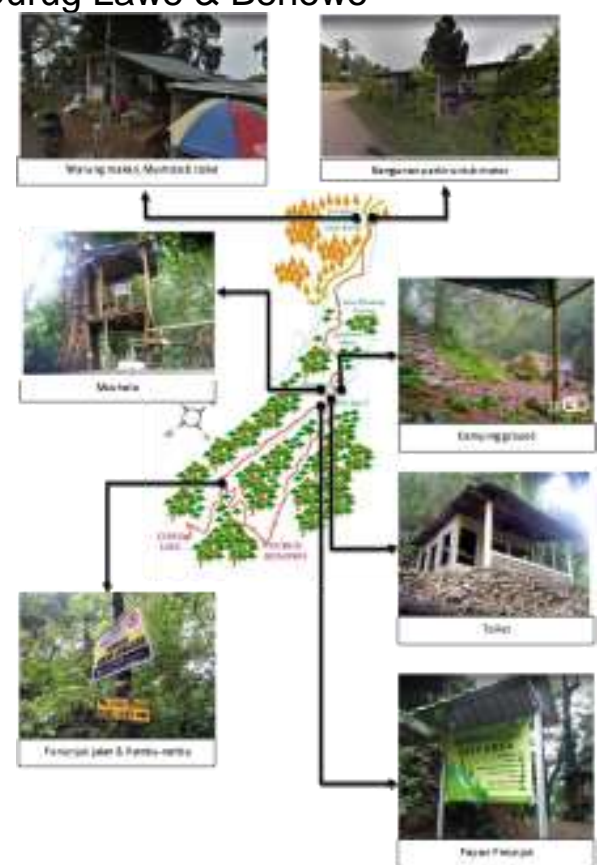

Gambar 4. Kondisi Fasilitas di object wisata Curu Lawe \& Benowo

Pada object wisata Curug Lawe \& Benowo terdapat fasilitas parkir yang begitu besar untuk roda 2 dan roda 4. Terdapat Mushola, warung makan \& toilet di sekitar area parkir. Di sekitar perjalanan menuju object curug, terdapat banyak papan

Program Studi Arsitektur Universitas Pandanaran | kolaborasi jurnal@unpand.ac.id | 41 
penunjuk jalan dan papan himbauan keselamatan, sehingga perjalan terasa aman. Di beberapa tempat juga terdapat saung untuk berteduh untuk pengunjung Ketika turun hujan.

D. Ancilliary ( Lembaga Pelayanan) Curug Lawe \& Benowo

Curug Lawe dan Benowo memiliki lembaga di dalamnya,, yaitu Lembaga Masyarakat Desa Hutan (LMDH) Bela Pesona Curug Lawe Benowo Kalisidi (CLBK) yang berfungsi sebagai pangelola utama.

\section{Curug Semirang}

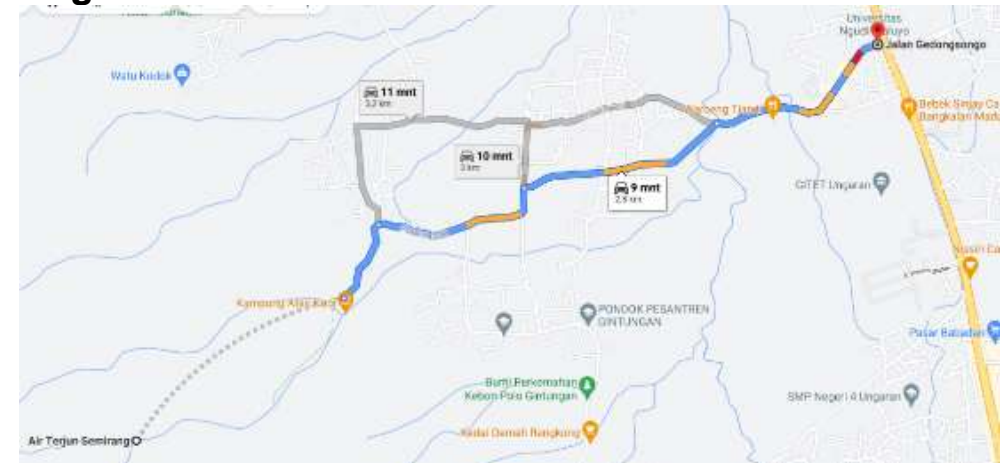

Gambar 5. Peta rute ke Curug Semirang Ungaran

A. Attraction ( Daya Tarik) Curug Semirang

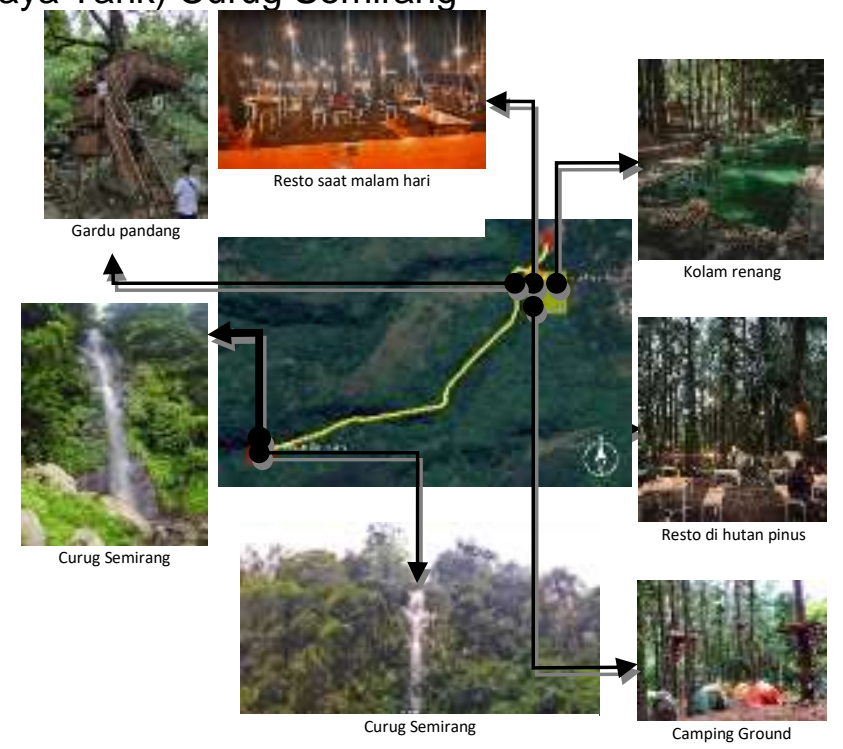

Gambar 6. Kondisi Daya Tarik Curug Semirang

Daya tarik utama object wisata ini adalah terdapat air terjun setinggi 40 meter yaitu Curug Semirang dan juga terdapat kolam renang dan kafetaria. Selain itu juga object wisata ini memiliki daya tarik dalam perjalan menuju tempat utama yaitu pemandangan alam hutan pinus yang terlindungi dan masih alami yang dapat dinikmati dari gardu pandang. Kolam renang menggunakan konsep natural dengan dinding kolam berupa bebatuan. Terdapat kolam kecil \& besar sehingga bisa untuk berenang orang dewasa maupun anak-anak.

B. Accessibility (Aksesbilitas) Curug Semirang

42 | Program Studi Arsitektur Universitas Pandanaran | kolaborasi jurnal@unpand.ac.id 


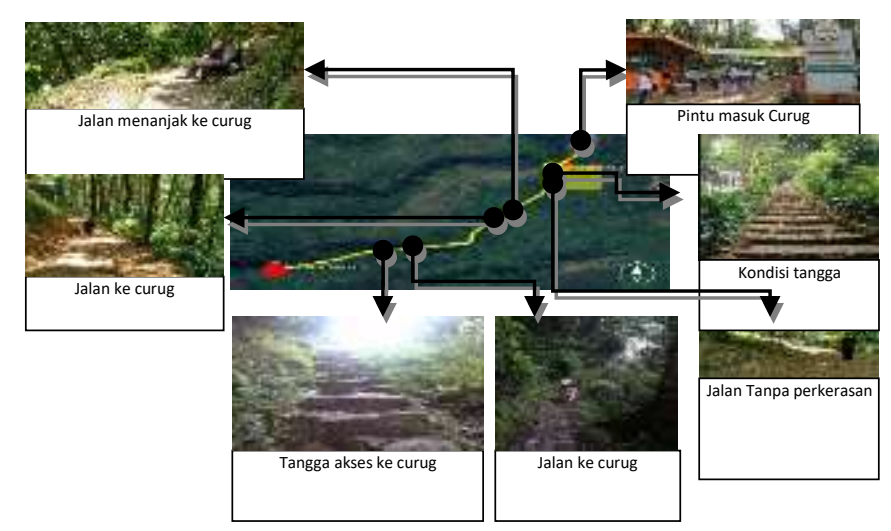

Gambar 7. Kondisi Aksesbilitas Curug Semirang

Untuk menuju lokasi, bisa melewati Jalan Gedongsongo, Gedanganak yang berada di belakang Kampus Universitas Ngudi Waluyo Semarang. Jarak Curug Semirang dengan kampus Ngudiwaluyo adalah 2,8 $\mathrm{Km}$ dan dapat ditempuh dengan mobil atau kendaraan roda dua selama kurang lebih 9 menit

C. Amenity ( Fasilitas) Curug Semirang
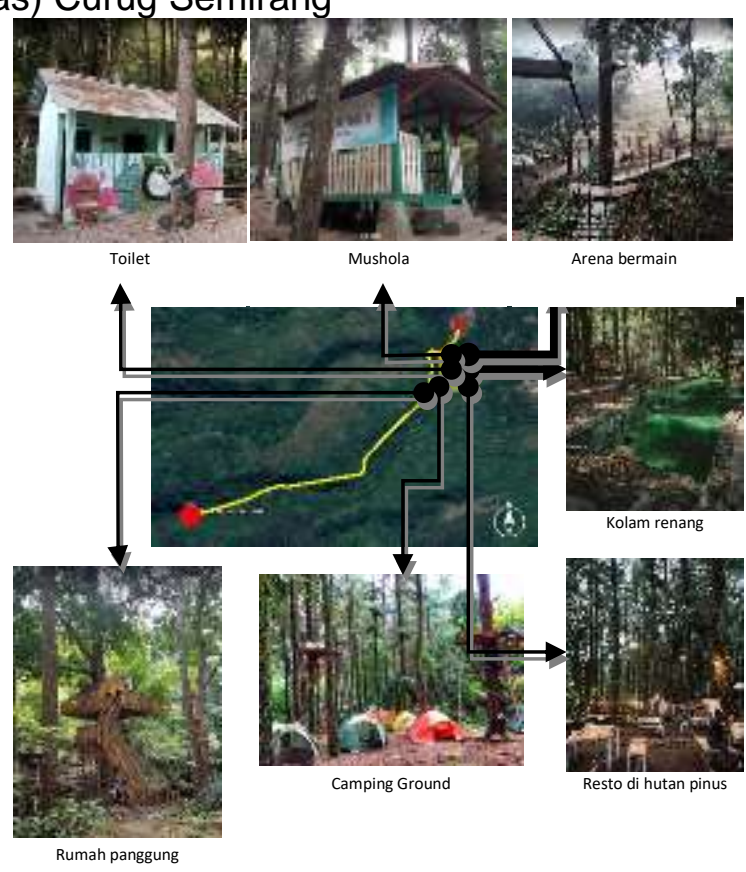

Gambar 8. Kondisi Fasilitas Curug Semirang

Pada object wisata Curug Semirang terdapat area parkir untuk roda 2 dan roda 4. Untuk sampai di loket masuk harus berjalan kurang lebih $100 \mathrm{~m}$. Di sekitar loket masuk juga terdapat fasilitas yang lumayan komplit, seperti Mushola, cafetaria, toilet dan bahkan terdapat kolam renang yang bisa digunakan untuk anak-anak hinga dewasa.

D. Ancilliary ( Lembaga Pelayanan) Curug Semirang

Curug Semirang memiliki lembaga pelayanan wisata, yaitu BUM Desa Gogik, yang berfungsi sebagai pangelola utama. BUM Desa adlah badan usaha yang dibentuk

Program Studi Arsitektur Universitas Pandanaran | kolaborasi jurnal@unpand.ac.id | 43 
oleh pemerintah desa bersama masyarakat. Dasar pendiriannya adalah Undangundang No.23 tahun 2014 tentang Pemerintah Daerah.

\section{Ngipik Pass}

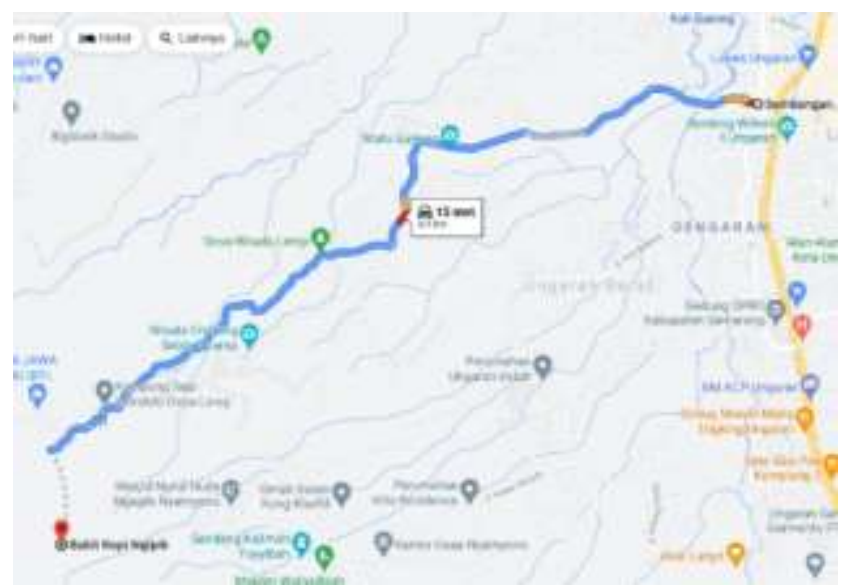

Gambar 9. Peta rute ke Curug Semirang

A. Attraction ( Daya Tarik) Ngipik Pass
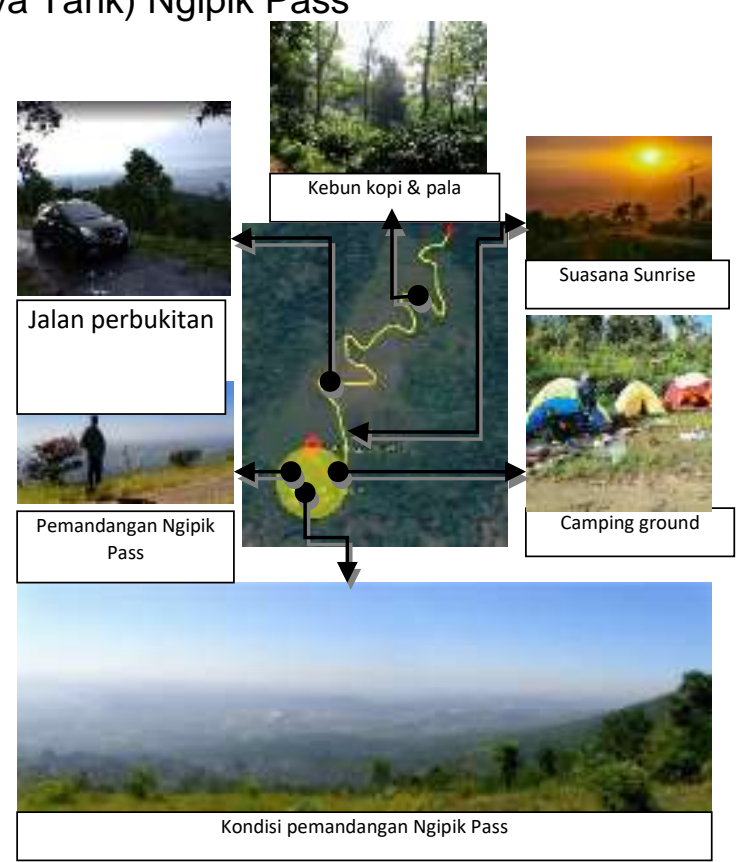

Gambar 10. Kondisi Daya Tarik Ngipik Pass

Daya tarik utama object wisata ini adalah merupakan sebuah dataran tinggi yang terletak di Ungaran dengan pemandangan yang indah untuk menikmati matahari terbit. Keberadaan tempat ini telah lama cukup dikenal oleh kalangan muda mudi di sekitar kota ungaran.

B. Accessibility (Aksesbilitas) Ngipik Pass 


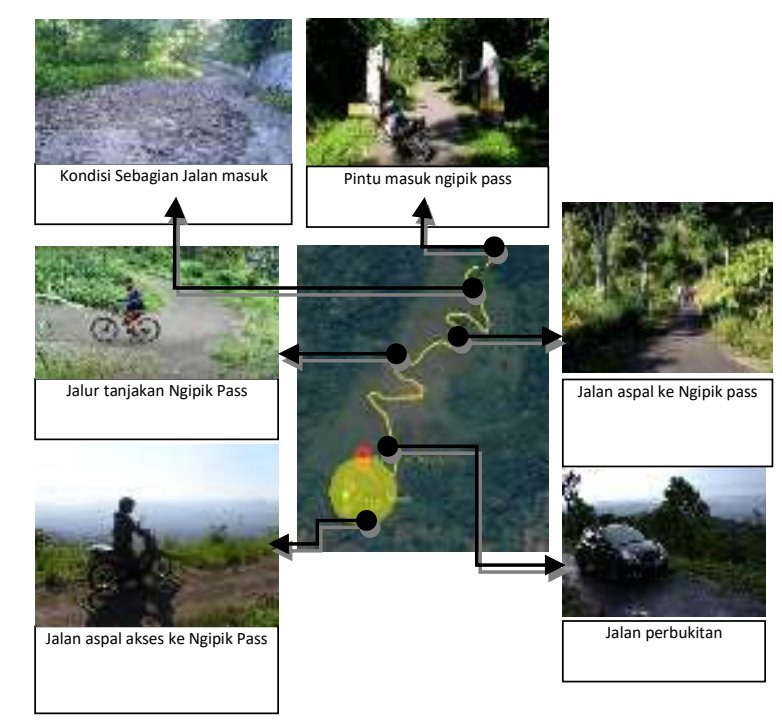

Gambar 11 .Kondisi Aksesbilitas Ngipik Pass

Untuk menuju lokasi puncak jalur Utama melewati jalan aspal Desa Lerep dan perkebunan kopi milik PT. Patra Jasa adalah jalan terpopuler dan sering dilewati. Jarak untuk ke Ngipik Pass adalah 4,9 Km dari titik awal adalah Alun-alun Ungaran.

C. Amenity ( Fasilitas) Ngipik Pass

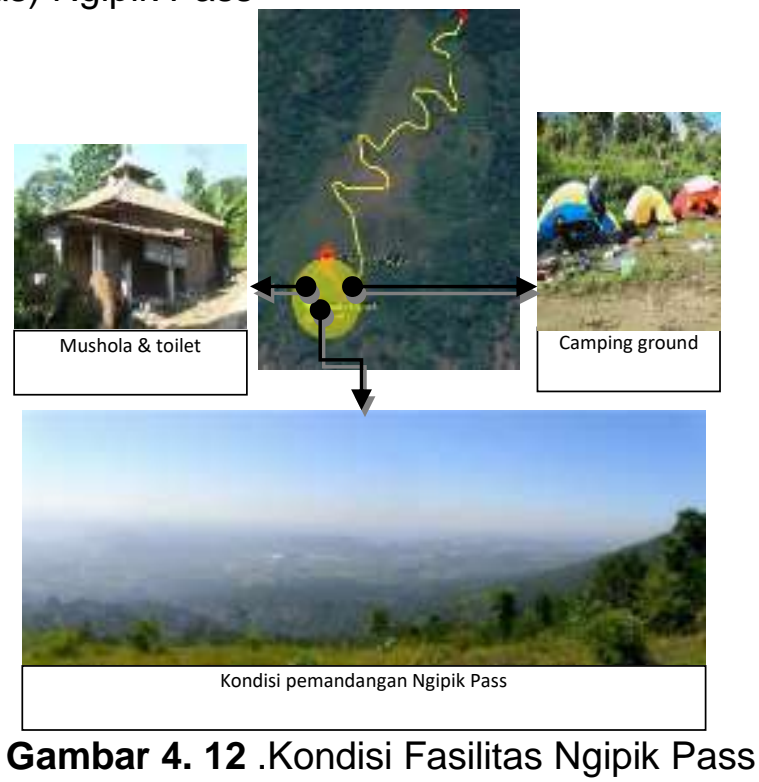

Pada object wisata Ngipik Pass terdapat area parkir untuk roda 2 dan roda 4. Untuk sampai di puncak dengan menggunakan kendaraan roda dua atau empat membutuhkan waktu kurang lebih 15 menit. Fasilitas yang ada adalah berupa Area pandang, Camping ground, toilet \& mushola. Masih banyak keterbatasan masalah fasilitas yang ada dikarenakan banyak yang belum tau akan object wisata ini,, sehingga belum ada campur tangan lebih untuk mengembangkan falisitas dari pemerintah.

D. Ancilliary ( Lembaga Pelayanan) Ngipik Pass

Ngipik Pass memiliki lembaga pelayanan wisata, yaitu BUM Desa Gogik, yang berfungsi sebagai pangelola utama.

Program Studi Arsitektur Universitas Pandanaran | kolaborasi jurnal@unpand.ac.id | 45 
Matriks penilaian Attraction / daya tarik object wisata.

Pada tabel 1 dapat diketahui bahwa Curug Lawe \& Benowo merniliki 4 unsur daya tarik objek wisata berupa keindahan alam yaitu : pandangan lepas menuju object, Pandangan lepas keluar object, variasi pandangan di dalam object \& kondisi lingkungan object sehingga mendapat nilai 40. Untuk Curug Semirang merniliki 5 unsur daya tarik objek wisata berupa : pandangan lepas menuju object, Pandangan lepas keluar object, variasi pandangan di dalam object, keserasian bangunan \& kondisi lingkungan object sehingga mendapat nilai 50. Sedangkan untuk Curug Semirang merniliki 4 unsur daya tarik objek wisata .

Tabel 1. Penilaian Attraction ( Daya Tarik) object wisata (Bobot 10)

\begin{tabular}{clccc}
\hline No & \multicolumn{3}{c}{ Unsur/ Sub Unsur } & \multicolumn{3}{c}{ Nilai } \\
\hline 1 & $\begin{array}{l}\text { Keindahan Alam } \\
\begin{array}{l}\text { a. Pandangan lepas } \\
\text { menuju object }\end{array}\end{array}$ & Curug Lawe \& Benowo & Curug Semirang & Ngipik Pass \\
\hline $\begin{array}{l}\text { b. Pandangan lepas } \\
\text { keluar Object }\end{array}$ & $\mathrm{V}$ & $\mathrm{V}$ & $\mathrm{V}$ \\
\hline $\begin{array}{l}\text { c. Variasi pandangan } \\
\text { di dalam Object }\end{array}$ & $\mathrm{V}$ & $\mathrm{V}$ & $\mathrm{V}$ \\
\hline $\begin{array}{l}\text { d. Keserasian } \\
\text { bangunan }\end{array}$ & $\mathrm{V}$ & $\mathrm{V}$ & $\mathrm{V}$ \\
\hline $\begin{array}{l}\text { e. Kondisi lingkungan } \\
\text { object }\end{array}$ & $\mathrm{X}$ & $\mathrm{V}$ & $\mathrm{X}$ \\
\hline \multicolumn{1}{c}{ Total Poin } & $\mathrm{V}$ & $\mathrm{V}$ & $\mathrm{V}$ \\
\hline
\end{tabular}

Pada tabel 2 dapat diketahui bahwa Curug Lawe \& Benowo, Curug Semirang \& Ngipik Pass merniliki 4 unsur daya tarik objek wisata berupa keunikan sumber daya alam.

Tabel 2. Penilaian Attraction ( Daya Tarik) object wisata (Bobot 10)

\begin{tabular}{|c|c|c|c|c|}
\hline No & Unsur/ Sub Unsur & & Nilai & \\
\hline \multirow{7}{*}{2} & $\begin{array}{c}\text { Keunikan Sumber Daya } \\
\text { Alam }\end{array}$ & Curug Lawe \& Benowo & Curug Semirang & Ngipik Pass \\
\hline & a.Sumber mata air & V & V & V \\
\hline & b. Flora & V & V & V \\
\hline & c. Fauna & V & V & V \\
\hline & d. Adat istiadat/ budaya & $\mathrm{X}$ & $\mathrm{X}$ & $x$ \\
\hline & e. Pemandangan alam & V & V & V \\
\hline & Total Poin & 40 & 40 & 40 \\
\hline
\end{tabular}

Pada tabel 3 dapat diketahui bahwa Curug Lawe \& Benowo merniliki 5 unsur daya tarik objek wisata berupa banyaknya jenis SDA yang menonjol yaitu : bebatuan, flora, fauna, air \& gejala alam sehingga mendapat nilai 50. Untuk Curug Semirang merniliki 5 unsur daya tarik objek wisata berupa : bebatuan, flora, fauna, air \& gejala alam sehingga mendapat nilai 50. Sedangkan untuk Curug Semirang merniliki 3 
unsur daya tarik objek wisata berupa :flora, fauna, air \& gejala alam sehingga mendapat nilai 40.

Tabel 3. Penilaian Attraction ( Daya Tarik) object wisata (Bobot 10)

\begin{tabular}{|c|c|c|c|c|}
\hline No & Unsur/ Sub Unsur & \multicolumn{3}{|c|}{ Nilai } \\
\hline \multirow{7}{*}{3} & $\begin{array}{c}\text { Banyaknya jenis SDA yang } \\
\text { menonjol }\end{array}$ & Curug Lawe \& Benowo & Curug Semirang & Ngipik Pass \\
\hline & a. Bebatuan & $\mathrm{V}$ & V & $\mathrm{x}$ \\
\hline & b. Flora & V & V & $\mathrm{V}$ \\
\hline & c. Fauna & V & $\mathrm{V}$ & $\mathrm{V}$ \\
\hline & d. Air & $\mathrm{V}$ & $\mathrm{V}$ & $\mathrm{V}$ \\
\hline & e. Gejala alam & $\mathrm{V}$ & $\mathrm{V}$ & $\mathrm{V}$ \\
\hline & Total Poin & 50 & 50 & 40 \\
\hline
\end{tabular}

Pada tabel 4 dapat diketahui bahwa Curug Lawe \& Benowo merniliki 5 unsur daya tarik objek wisata berupa kepekaan SDA yang menonjol yaitu : Geologi/bebatuan, flora, fauna, erosi \& ekosistem sehingga mendapat nilai 50. Untuk Curug Semirang merniliki 5 unsur daya tarik objek wisata berupa : Geologi/bebatuan, flora, fauna, erosi \& ekosistem sehingga mendapat nilai 50. Sedangkan untuk Curug Semirang merniliki 3 unsur daya tarik objek wisata berupa :flora, fauna, \& ekosistem sehingga mendapat nilai 30 .

Tabel 4. Penilaian Attraction ( Daya Tarik) object wisata (Bobot 10)

\begin{tabular}{|c|c|c|c|c|}
\hline No & Unsur/ Sub Unsur & & Nilai & \\
\hline \multirow{7}{*}{4} & $\begin{array}{c}\text { Kepekaan sumber daya } \\
\text { alam }\end{array}$ & Curug Lawe \& Benowo & Curug Semirang & Ngipik Pass \\
\hline & a. Geologi/ Bebatuan & V & V & $\mathrm{X}$ \\
\hline & b. Flora & $\mathrm{V}$ & $\mathrm{V}$ & V \\
\hline & c. Fauna & $\mathrm{V}$ & $\mathrm{V}$ & $\mathrm{V}$ \\
\hline & d. Erosi & $\mathrm{V}$ & $\mathrm{V}$ & $x$ \\
\hline & e. Eko sistem & V & V & V \\
\hline & Total Poin & 50 & 50 & 30 \\
\hline
\end{tabular}

Pada tabel 5 dapat diketahui bahwa Curug Lawe \& Benowo merniliki 4 unsur daya tarik objek wisata. Untuk Curug Semirang merniliki 5. Sedangkan untuk Ngipik Pass merniliki 5 unsur daya tarik objek wisata berupa : tracking, mendaki, camping, pendidikan \& tempat bersepeda sehingga mendapat nilai 50.

Tabel 5. Penilaian Attraction ( Daya Tarik) object wisata (Bobot 10)

\begin{tabular}{|c|c|c|c|c|}
\hline No & Unsur/ Sub Unsur & & Nilai & \\
\hline \multirow{8}{*}{5} & Aktifitas wisata & Curug Lawe \& Benowo & Curug Semirang & Ngipik Pass \\
\hline & a. Tracking & V & V & $\mathrm{V}$ \\
\hline & b. Mendaki & $\mathrm{V}$ & V & V \\
\hline & c. Renang & $X$ & V & $X$ \\
\hline & d. Camping & $\mathrm{V}$ & $\mathrm{V}$ & $\mathrm{V}$ \\
\hline & e. Pendidikan & V & $\mathrm{V}$ & V \\
\hline & f. Bersepeda & $x$ & $x$ & V \\
\hline & Total Poin & 40 & 50 & 50 \\
\hline
\end{tabular}

Program Studi Arsitektur Universitas Pandanaran | kolaborasi jurnal@unpand.ac.id | 47 
Pada tabel 6 dapat diketahui bahwa Curug Lawe \& Benowo merniliki 5 unsur daya tarik objek wisata berupa kebersihan lokasi.

Tabel 6. Penilaian Attraction ( Daya Tarik) object wisata (Bobot 10)

\begin{tabular}{|c|c|c|c|c|}
\hline No & Unsur/ Sub Unsur & & Nilai & \\
\hline \multirow{7}{*}{6} & Kebersihan lokasi & Curug Lawe \& Benowo & Curug Semirang & Ngipik Pass \\
\hline & a. Alam / lingkungan & $\mathrm{V}$ & $\mathrm{V}$ & $\mathrm{x}$ \\
\hline & b. Fasilitas & V & $\mathrm{V}$ & $\mathrm{x}$ \\
\hline & c. Jalan & $\mathrm{V}$ & $\mathrm{V}$ & V \\
\hline & d. Air & $\mathrm{V}$ & $\mathrm{V}$ & $\mathrm{V}$ \\
\hline & $\begin{array}{l}\text { e. Terjaganya Vandalisme/ } \\
\text { coret coret }\end{array}$ & $\mathrm{V}$ & $\mathrm{V}$ & $\mathrm{V}$ \\
\hline & $\begin{array}{l}\text { Total Poin } \\
\end{array}$ & 50 & 50 & 30 \\
\hline
\end{tabular}

Pada tabel 7 dapat diketahui bahwa Curug Lawe \& Benowo merniliki 3 unsur daya tarik objek wisata berupa keamanan Kawasan.

Tabel 7. Penilaian Attraction ( Daya Tarik) object wisata (Bobot 10)

\begin{tabular}{clcccc}
\hline No & \multicolumn{1}{c}{ Unsur/ Sub Unsur } & \multicolumn{3}{c}{ Nilai } \\
\hline \multirow{1}{*}{ Keamanan kawasan } & Curug Lawe \& Benowo & Curug Semirang & Ngipik Pass \\
\cline { 2 - 6 } & $\begin{array}{l}\text { a. Bencana alam / } \\
\text { lingkungan }\end{array}$ & $\mathrm{X}$ & $\mathrm{X}$ & $\mathrm{V}$ \\
\cline { 2 - 6 } & b. Fasilitas & $\mathrm{V}$ & $\mathrm{V}$ & $\mathrm{V}$ \\
\cline { 2 - 6 } & c. Jalan & $\mathrm{X}$ & $\mathrm{X}$ & $\mathrm{V}$ \\
\cline { 2 - 6 } & d. Gangguan Manusia & $\mathrm{V}$ & $\mathrm{V}$ & $\mathrm{V}$ \\
\cline { 2 - 6 } & e. Gangguan Fauna & $\mathrm{V}$ & $\mathrm{V}$ & $\mathrm{V}$ \\
\cline { 2 - 6 } & \multicolumn{2}{c}{ Total Poin } & $\mathbf{3 0}$ & $\mathbf{3 0}$ & $\mathbf{5 0}$ \\
\hline
\end{tabular}

\section{Matriks penilaian Accesibility / Aksesbilitas}

Pada tabel 8 dapat diketahui bahwa Curug Lawe \& Benowo memiliki 3 unsur aksesbilitas objek wisata berupa Kondisi jalan darat dari lbu kota Provinsi.

Tabel 8. Penilaian Accesibility ( Aksesbilitas) object wisata (Bobot 10)

\begin{tabular}{|c|c|c|c|c|}
\hline No & Unsur/ Sub Unsur & & Nilai & \\
\hline \multirow{6}{*}{1} & $\begin{array}{c}\text { Kondisi jalan darat dari lbu } \\
\text { kota Provinsi }\end{array}$ & Curug Lawe \& Benowo & Curug Semirang & Ngipik Pass \\
\hline & a. $<1$ Kilometer & $\mathrm{x}$ & $\mathrm{x}$ & V \\
\hline & b. $<5$ Kilometer & V & V & V \\
\hline & c. $<15$ Kilometer & V & V & $\mathrm{V}$ \\
\hline & d. $>30$ Kilometer & $\mathrm{V}$ & $\mathrm{V}$ & $\mathrm{V}$ \\
\hline & Total Poin & 30 & 30 & 40 \\
\hline
\end{tabular}

Pada tabel 9 dapat diketahui bahwa Curug Lawe \& Benowo, Curug Semirang \& Ngipik Pass memiliki 3 unsur aksesbilitas objek wisata berupa Bandara udara internasional / domestic.

Tabel 9. Penilaian Accesibility ( Aksesbilitas) object wisata (Bobot 10)

No Unsur/ Sub Unsur Nilai

48 | Program Studi Arsitektur Universitas Pandanaran | kolaborasi jurnal@unpand.ac.id 


\begin{tabular}{llccc}
\hline \multicolumn{1}{c}{$\begin{array}{c}\text { Bandara udara } \\
\text { internasional / domestik }\end{array}$} & Curug Lawe \& Benowo & Curug Semirang & Ngipik Pass \\
\cline { 2 - 5 } $\begin{array}{l}\text { a. Jayapura/ Pekanbaru/ } \\
\text { mabon/kupang }\end{array}$ & $\mathrm{X}$ & $\mathrm{X}$ & $\mathrm{X}$ \\
\cline { 2 - 5 } & b. Medan/ Manado & $\mathrm{X}$ & $\mathrm{X}$ & $\mathrm{X}$ \\
\hline c. Denpasar & $\mathrm{V}$ & $\mathrm{V}$ & $\mathrm{V}$ \\
\hline d. Jakarta & $\mathrm{V}$ & $\mathrm{V}$ & $\mathrm{V}$ \\
\hline E. Jogja & $\mathrm{V}$ & $\mathrm{V}$ & $\mathrm{V}$ \\
\hline \multicolumn{1}{c}{ Total Poin } & 30 & 30 & 30 \\
\hline
\end{tabular}

Pada tabel 10 dapat diketahui bahwa Curug Lawe \& Benowo, Curug Semirang \& Ngipik Pass memiliki 1 unsur aksesbilitas objek wisata berupa Waktu tempuh dari ibukota ( kendaraan roda $2-4$ )

Tabel 10. Penilaian Accesibility (Aksesbilitas) object wisata (Bobot 10)

\begin{tabular}{cccccc}
\hline No & \multicolumn{1}{c}{ Unsur/ Sub Unsur } & \multicolumn{3}{c}{ Nilai } \\
\hline \multirow{6}{*}{$\begin{array}{c}\text { Waktu tempuh dari ibukota } \\
\text { ( kendaraan roda 2-4) }\end{array}$} & Curug Lawe \& Benowo & Curug Semirang & Ngipik Pass \\
\cline { 2 - 6 } 3 & a. Ibu kota Provinsi & $\mathrm{V}$ & $\mathrm{V}$ & $\mathrm{V}$ \\
\cline { 2 - 6 } & b. Ibu kota Negara & $\mathrm{X}$ & $\mathrm{X}$ & $\mathrm{X}$ \\
\cline { 2 - 6 } & \multicolumn{2}{c}{ Total Poin } & 10 & 10 & 10 \\
\hline
\end{tabular}

Pada tabel 11 dapat diketahui bahwa Curug Lawe \& Benowo, Curug Semirang \& Ngipik Pass memiliki 2 unsur aksesbilitas objek wisata berupa Frekunsi kendaraan umum dari pusat informasi ke object yaitu : Frekuensi paling banyak menggunakan minibus / kendaraan pribadi \& Ojek online sehingga mendapatkan nilai 20 poin.

Tabel 11. Penilaian Accesibility (Aksesbilitas) object wisata (Bobot 10)

\begin{tabular}{|c|c|c|c|c|}
\hline No & Unsur/ Sub Unsur & & Nilai & \\
\hline \multirow{5}{*}{4} & $\begin{array}{c}\text { Frekunsi kendaraan umum } \\
\text { dari pusat informasi ke } \\
\text { object }\end{array}$ & Curug Lawe \& Benowo & Curug Semirang & Ngipik Pass \\
\hline & a. Bus & $\mathrm{X}$ & $X$ & $\mathrm{X}$ \\
\hline & $\begin{array}{l}\text { b. Mini Bus / Kendaraan } \\
\text { Pribadi }\end{array}$ & V & V & V \\
\hline & c. Ojek Online & V & V & V \\
\hline & Total Poin & 20 & 20 & 20 \\
\hline
\end{tabular}

\section{Matriks penilaian Aminity / Fasilitas}

Pada tabel 12 dapat diketahui bahwa Curug Semirang memiliki unsur fasilias objek wisata berupa sarana yang paling banyak dengan 60 poin, disusul Curug Lawe \& benowo dengan 30 poin dan Ngipik Pass 20 Poin

Tabel 12. Penilaian Amenity ( Fasilitas) object wisata (Bobot 10)

\begin{tabular}{lccc}
\hline \multicolumn{1}{c}{ Unsur/ Sub Unsur } & \multicolumn{3}{c}{ Nilai } \\
\multicolumn{1}{c}{ Sarana } & Curug Lawe \& Benowo & Curug Semirang & Ngipik Pass \\
\hline a. Penginapan & $\mathrm{X}$ & $\mathrm{X}$ & $\mathrm{X}$ \\
\hline b. Area camping & $\mathrm{V}$ & $\mathrm{V}$ & $\mathrm{V}$ \\
\hline c. Rumah makan/ minum & $\mathrm{V}$ & $\mathrm{V}$ & $\mathrm{X}$ \\
\hline
\end{tabular}

Program Studi Arsitektur Universitas Pandanaran | kolaborasi jurnal@unpand.ac.id | 49 


\begin{tabular}{llcc}
\hline d. Kolam renang & $X$ & $V$ & $X$ \\
\hline e. Area parkir & V & V & V \\
\hline f. Kios cendramata & $X$ & $V$ & $X$ \\
\hline g. Arena permainan & $X$ & $V$ & $X$ \\
\hline \multicolumn{1}{c}{ Total Poin } & 30 & 60 & 20 \\
\hline
\end{tabular}

Pada tabel 13 dapat diketahui bahwa Curug Lawe \& Benowo dan Curug Semirang memiliki unsur fasilias objek wisata berupa Prasarana dengan nilai sama yaitu 80 poin, disusul Ngipik pass dengan 60 poin.

Tabel 13. Penilaian Amenity ( Fasilitas) object wisata (Bobot 10) Unsur/ Sub Unsur Nilai

\begin{tabular}{lccc}
\hline \multicolumn{1}{c}{ Prasarana } & Curug Lawe \& Benowo & Curug Semirang & Ngipik Pass \\
\hline a. Jalan & $\mathrm{V}$ & $\mathrm{V}$ & $\mathrm{V}$ \\
\hline b. Jembatan & $\mathrm{V}$ & $\mathrm{V}$ & $\mathrm{V}$ \\
\hline c. Area parkir & $\mathrm{V}$ & $\mathrm{V}$ & $\mathrm{V}$ \\
\hline d. Jaringan listrik & $\mathrm{V}$ & $\mathrm{V}$ & $\mathrm{X}$ \\
\hline e. Jaringan air minum & $\mathrm{V}$ & $\mathrm{V}$ & $\mathrm{V}$ \\
\hline f. Jaringan telfon & $\mathrm{V}$ & $\mathrm{V}$ & $\mathrm{V}$ \\
\hline g. Dainase / saluran & $\mathrm{V}$ & $\mathrm{V}$ & $\mathrm{V}$ \\
\hline h. Sistem pembuangan limbah & $\mathrm{V}$ & $\mathrm{V}$ & $\mathrm{X}$ \\
\hline \multicolumn{1}{c}{ Total Poin } & 80 & 80 & 60 \\
\hline
\end{tabular}

Dapat diketahui bahwa Curug Lawe \& Benowo dan Curug Semirang dan Ngipik Pass memiliki unsur fasilias objek wisata berupa ketersediaan air bersih dengan nilai sama yaitu 50 poin yang berarti ketersediaan air bersih di obyek wisata tersebut sangatlah baik.

Tabel 14. Penilaian Amenity ( Fasilitas) object wisata (Bobot 10)

\begin{tabular}{lccc}
\hline \multicolumn{1}{c}{ Unsur/ Sub Unsur } & \multicolumn{3}{c}{ Nilai } \\
\hline \multicolumn{1}{c}{ Ketersediaan air bersih } & Curug Lawe \& Benowo & Curug Semirang & Ngipik Pass \\
\hline a. Volume & $\mathrm{V}$ & $\mathrm{V}$ & $\mathrm{V}$ \\
\hline b. Kemudahan & $\mathrm{V}$ & $\mathrm{V}$ & $\mathrm{V}$ \\
\hline c. Kelayakan & $\mathrm{V}$ & $\mathrm{V}$ & $\mathrm{V}$ \\
\hline d. Ketersediaan & $\mathrm{V}$ & $\mathrm{V}$ & $\mathrm{V}$ \\
\hline e. Pengelolaan & $\mathrm{V}$ & $\mathrm{V}$ & $\mathrm{V}$ \\
\hline \multicolumn{1}{c}{ Total Poin } & 50 & 50 & 50 \\
\hline
\end{tabular}

\section{Matriks penilaian Ancilliary / Kelembagaan}

Pada tabel 15 dapat diketahui bahwa Curug Lawe \& Benowo dan Curug Semirang memiliki unsur Ancilliary objek wisata berupa keamanan pengunjung dengan nilai 20 poin, dan Ngipik pass mendapat nilai keamanan pengunjung tertinggi yaitu 50 poin.

Tabel 15. Penilaian Ancilliary (Kelembagaan) object wisata (Bobot 10)

\begin{tabular}{ccccc}
\hline No & Unsur/ Sub Unsur & Nilai & \\
\hline & Keamanan Pengunjung & Curug Lawe \& Benowo & Curug Semirang & Ngipik Pass \\
\hline
\end{tabular}

50 | Program Studi Arsitektur Universitas Pandanaran | kolaborasi jurnal@unpand.ac.id 


\begin{tabular}{lllll}
\hline 1 & a. Kamtibnas & $\mathrm{V}$ & $\mathrm{V}$ & $\mathrm{V}$ \\
\cline { 2 - 5 } $\begin{array}{l}\text { b. Tidak ada bainatang } \\
\text { pengganggu }\end{array}$ & $\mathrm{V}$ & $\mathrm{V}$ & $\mathrm{V}$ \\
\hline $\begin{array}{l}\text { C. Tidak bahaya tanah } \\
\text { longsor }\end{array}$ & $\mathrm{X}$ & $\mathrm{X}$ & $\mathrm{V}$ \\
\hline $\begin{array}{l}\text { d.Keamanan Jalanan licin } \\
\begin{array}{l}\text { e. Keamanan dari puing- } \\
\text { puing }\end{array}\end{array}$ & $\mathrm{X}$ & $\mathrm{X}$ & $\mathrm{V}$ \\
\hline \multicolumn{1}{c}{ Total Poin } & $\mathbf{2 0}$ & $\mathrm{X}$ & $\mathrm{V}$ \\
\hline
\end{tabular}

Pada tabel 16 dapat diketahui bahwa Curug Lawe \& Benowo dan Curug Semirang memiliki unsur Ancilliary objek wisata berupa Kenyamanan pengunjung dengan nilai 30 poin, dan Ngipik pass mendapat nilai kenyamanan pengunjung yaitu 20 poin

Tabel 16. Penilaian Ancilliary (Kelembagaan) object wisata (Bobot 10)

\begin{tabular}{|c|c|c|c|c|}
\hline \multirow[t]{2}{*}{ No } & \multirow{2}{*}{$\begin{array}{c}\text { Unsur/ Sub Unsur } \\
\text { Kenyamanan Pengunjung }\end{array}$} & \multicolumn{3}{|c|}{ Nilai } \\
\hline & & Curug Lawe \& Benowo & Curug Semirang & Ngipik Pass \\
\hline \multirow[t]{6}{*}{2} & $\begin{array}{l}\text { a. Pembatasan waktu } \\
\text { kunjungan lebih lama }\end{array}$ & $x$ & $x$ & V \\
\hline & b. Pengarahan tempat wisata & V & V & $\mathrm{V}$ \\
\hline & c. Pemandu wisata & $\mathrm{x}$ & $x$ & $x$ \\
\hline & $\begin{array}{l}\text { d. Pusat informasi } \\
\text { pengunjung }\end{array}$ & $\mathrm{V}$ & V & $x$ \\
\hline & e. Pelayanan & V & V & $X$ \\
\hline & Total Poin & 30 & 30 & 20 \\
\hline
\end{tabular}

Pada tabel 17 dapat diketahui bahwa Curug Lawe \& Benowo dan Curug Semirang memiliki unsur Ancilliary objek wisata berupa pemasaran object wisata dengan nilai 40 poin, dan Ngipik pass mendapat nilai 10 poin.

Tabel 17. Penilaian Ancilliary (Kelembagaan) object wisata (Bobot 10)

\begin{tabular}{|c|c|c|c|c|}
\hline No & Unsur/ Sub Unsur & & Nilai & \\
\hline \multirow{6}{*}{3} & Pemasaran Object wisata & Curug Lawe \& Benowo & Curug Semirang & Ngipik Pass \\
\hline & a. Tarif harga terjangkau & V & V & V \\
\hline & b. Varian Produk wisata & V & V & $X$ \\
\hline & $\begin{array}{l}\text { c. Sarana penyampaian } \\
\text { informasi }\end{array}$ & $\mathrm{V}$ & V & $x$ \\
\hline & d. Promosi & V & V & $X$ \\
\hline & Total Poin & 40 & 40 & 10 \\
\hline
\end{tabular}

Pada tabel 18 dapat diketahui bahwa Curug Lawe \& Benowo memiliki unsur Ancilliary objek wisata berupa Target market wisata.

Tabel 18. Penilaian Ancilliary (Kelembagaan) object wisata (Bobot 10)

\begin{tabular}{cllllr}
\hline No & \multicolumn{2}{c}{ Unsur/ Sub Unsur } & \multicolumn{3}{c}{ Nilai } \\
\hline \multirow{3}{*}{4} & \multicolumn{1}{c}{ Target market wisata } & Curug Lawe \& Benowo & Curug Semirang & Ngipik Pass \\
\cline { 2 - 5 } & a. Anak-anak & $\mathrm{X}$ & $\mathrm{V}$ & $\mathrm{V}$ \\
\cline { 2 - 5 } & b. Keluarga & $\mathrm{V}$ & $\mathrm{V}$ & $\mathrm{V}$ \\
\cline { 2 - 5 } & c. Remaja & $\mathrm{V}$ & $\mathrm{V}$ & $\mathrm{V}$ \\
\cline { 2 - 5 } & d. Dewasa & $\mathrm{V}$ & $\mathrm{V}$ & $\mathrm{V}$ \\
\hline
\end{tabular}

Program Studi Arsitektur Universitas Pandanaran | kolaborasi jurnal@unpand.ac.id | 51 


\begin{tabular}{cccc} 
d. Orang tua & $X$ & $X$ & $V$ \\
\hline Total Poin & 30 & 40 & 50
\end{tabular}

Dari perhitungan ke 19 penilaian kuantitatif tersebut bisa dilihat di table 19 untuk Curug Lawe \& Benowo nilai total 710 poin, Curug Semirang 770 poin, untuk Ngipik pass 670 poin.

Tabel 19. Total penilaian object wisata

\begin{tabular}{|c|c|c|c|c|}
\hline \multirow[b]{2}{*}{ No } & \multirow[b]{2}{*}{ Unsur } & \multicolumn{3}{|c|}{ Nilai } \\
\hline & & $\begin{array}{c}\text { Curug Lawe \& } \\
\text { Benowo }\end{array}$ & Curug Semirang & Ngipik Pass \\
\hline 1 & Keindahan Alam & 40 & 50 & 40 \\
\hline 2 & Keunikan Sumber Daya Alam & 40 & 40 & 40 \\
\hline 3 & $\begin{array}{l}\text { Banyaknya jenis SDA yang } \\
\text { menonjol }\end{array}$ & 50 & 50 & 40 \\
\hline 4 & Keutuhan sumber daya alam & 40 & 40 & 30 \\
\hline 5 & Kepekaan sumber daya alam & 50 & 50 & 30 \\
\hline 6 & Aktifitas wisata & 40 & 50 & 50 \\
\hline 7 & Kebersihan lokasi & 50 & 50 & 30 \\
\hline 8 & Keamanan kawasan & 30 & 30 & 50 \\
\hline 9 & $\begin{array}{l}\text { Kondisi jalan darat dari lbu kota } \\
\text { Provinsi }\end{array}$ & 30 & 30 & 40 \\
\hline 10 & $\begin{array}{l}\text { Bandara udara internasional / } \\
\text { domestik }\end{array}$ & 30 & 30 & 30 \\
\hline 11 & $\begin{array}{l}\text { Waktu tempuh dari ibukota ( } \\
\text { kendaraan roda } 2-4 \text { ) }\end{array}$ & 10 & 10 & 10 \\
\hline 12 & $\begin{array}{l}\text { Frekunsi kendaraan umum dari } \\
\text { pusat informasi ke object }\end{array}$ & 20 & 20 & 20 \\
\hline 13 & Sarana & 30 & 60 & 20 \\
\hline 14 & Prasarana & 80 & 80 & 60 \\
\hline 15 & Ketersediaan air bersih & 50 & 50 & 50 \\
\hline 16 & Keamanan Pengunjung & 20 & 20 & 50 \\
\hline 17 & Kenyamanan Pengunjung & 30 & 30 & 20 \\
\hline 18 & Pemasaran Object wisata & 40 & 40 & 10 \\
\hline 19 & Target market wisata & 30 & 40 & 50 \\
\hline & Total Poin & 710 & 770 & 670 \\
\hline
\end{tabular}

Pengklasifikasian tingkat kelayakan wisata dengan pendekatan 4A menggunakan perhitungan: 1. Rendah, 2. Sedang, 3. Tinggi yang didapat dari nilai maksimal dan nilai minimal kriteria penilaian 4A. Bisa dilihat pada table 4.20. Sehingga dapat dihasilkan bahwa Curug Lawe \& Benowo memiliki potensi wisata yang tinggi (710), untuk Curug Semirang memiliki potensi wisata tinggi (770) dan untuk Ngipik Pass memiliki nilai sedang (670) untuk dikembangkan menjadi daerah wisata unggulan.

Tabel 20. Klasifikasi nilai

\begin{tabular}{ccccc}
\hline \multirow{2}{*}{ No } & \multirow{3}{*}{ Obyek Wisata } & \multicolumn{3}{c}{ Nilai } \\
\cline { 3 - 5 } & & $691-920$ & $461-690$ & $>460$ \\
\cline { 3 - 5 } & & $($ Tinggi $)$ & ( Sedang) & (Rendah) \\
\hline 1 & Curug Lawe \& Benowo & 710 & \\
\hline 2 & Curug Semirang & 770 & \\
\hline 3 & Ngipik Pass & & 670 & \\
\hline
\end{tabular}




\section{KESIMPULAN}

Berdasarkan hasil penelitian yang sudah dilakukan terdapat beberapa hal yang harus dilakukan yaitu untuk mewujudkan berkembanya wisata di Curug Lawe \& Benowo, Curug Semirang \& Ngipik Pass agar menjadikan wisata tersebut lebih layak untuk dikunjungi. Dan untuk pengembangannya diharuskan melakukan koordinasi kepada berbagai pihak yang terkait dalam hal pariwisata khususnya dalam penyediaan fasilitas dan juga sarana lainnya seperti sarana akomodasi, transportasi dan sarana penunjang lainnya. Sumber dana dari pembiayaan pengembangan obyek wisata dapat diperoleh dari sumber dasar, yaitu dari pendapatan obyek wisata itu sendiri dan juga bantuan dari pemerintah maupun Kerjasama kepada pihak swasta.

\section{DAFTAR PUSTAKA}

Setiawan, I. (2015). Identifikasi Potensi Wisata Beserta 4a (Attraction, Amenity, Accessibility, Ancilliary) Di Dusun Sumber Wangi, Desa Pemuteran, Kecamatan Gerokgak, Kabupaten Buleleng, Bali Nama.

Dewi Yanti. "Perencanaan Prototipe Sistem Informasi Pariwisata Berbasis Web Di Kabupaten Dairi Sumatera Utara", Khasanah IImu - Jurnal Pariwisata Dan Budaya, 2018

Praniti, D. L. \& T. (2015). Strategi Pengembangan Pariwisata Kota Semarang (Studi Kasus Peningkatan Obyek Wisata Taman Margasatwa Semarang). FISIPJurusan Administrasi Publik, Universitas Diponegoro, I, 1-16.

Buditiawan, K., \& Harmono. (2020). Strategi Pengembangan Destinasi Pariwisata Kabupaten Jember. Jurnal Kebijakan Pembangunan, 15(1), 37-50.

Susanti, A. D., \& Mandaka, M. (2019). Evaluation on Sumber Seneng Natural Park, Rembang As Tourism Object Using Ado-Odtwa Analysis. In Modul (Vol. 19, Issue 1, p. 25).

Kasus, S., Pangandaran, P., Ciamis, K., Barat, J., \& Hidayat, M. (2011). STRATEGI PERENCANAAN DAN PENGEMBANGAN OBJEK WISATA (STUDI KASUS PANTAI PANGANDARAN KABUPATEN CIAMIS JAWA BARAT) Marceilla Hidayat Politeknik Negeri Bandung. Tourism and Hospitality Essentials (THE) Journal, I(1), 33-44.

Praniti, D. L. \& T. (2015). Strategi Pengembangan Pariwisata Kota Semarang (Studi Kasus Peningkatan Obyek Wisata Taman Margasatwa Semarang). FISIPJurusan Administrasi Publik, Universitas Diponegoro, I, 1-16.

Praniti, D. L. \& T. (2015). Strategi Pengembangan Pariwisata Kota Semarang (Studi Kasus Peningkatan Obyek Wisata Taman Margasatwa Semarang). FISIPJurusan Administrasi Publik, Universitas Diponegoro, I, 1-16.

Setya, M. V. (2017). Semarang Dalam Upaya Mengembangkan Pariwisata Kota Semarang. Journal of Politics and Government Studies, 6, 410-401.

li, B. A. B., and Tinjauan Pustaka. 2010. "(2) Obyek Wisata Sosial Budaya, (3) Obyek Wisata Minat Khusus ( Special Interest ), Menurut UU Nomor 10 Tahun 2009 Tentang Kepariwisataan, Daerah Tujuan." 6-14.

Waskito, Suyatmin, Edy Purwo, Fakultas Ekonomi, Universitas Muhammadiyah Surakarta, JI A. Yani, Tromol Pos, Fakultas Ekonomi, Universitas Muhammadiyah Surakarta, JI A. Yani, and Tromol Pos. 2017. "Potensi Daya Tarik Wisata Sejarah Budaya." Potensi Daya Tarik Wisata Sejarah Budaya 744-51. 
54 | Program Studi Arsitektur Universitas Pandanaran | kolaborasi_jurnal@unpand.ac.id 